\title{
Fuzzy PID Model -Based Study on Idle Control of Gas Engine
}

\author{
Ge Xiaocheng ${ }^{1,2 *}$, Xu Zhongming ${ }^{1}$, Li Jingbo ${ }^{2}$ and Zou Bowen ${ }^{2}$ \\ ${ }^{1}$ The State Key Laboratory of Mechanical Transmission, Chongqing University, Chongqing, 400030, China; ${ }^{2}$ China \\ Automotive Engineering Research Institute, Chongqing, 400039 China
}

\begin{abstract}
Nowadays, natural gas conforms to the conditions of environmental protection and renewable energy, which plays a significant role in the future development of mankind. It has made some progress in applying natural gas to the automotive industry. As we all know that the source power of automobile comes from engine, therefore, based on the study on the control algorithm of gas engine, this paper aims to provide theoretical basis for further application of gas engine. This paper analyzed PID control algorithm, fuzzy control algorithm and fuzzy PID control algorithm, designed corresponding controllers based on the algorithm principles, applied these three algorithms to the idle control process of the automobile gas engine. This paper concluded that the fuzzy PID control algorithm is of higher superiority through contrastive analysis on the control effects of theses three algorithm in the process of cooling high idle start, switching high idle to low idle and switching low idle to high idle.
\end{abstract}

Keywords: Fuzzy control, fuzzy PID control, gas engine, idle control, PID control, SOFC.

\section{INTRODUCTION}

Natural gas engine came into being in 1872, Italian used natural gas as the automobile fuel in early 1930s, gas vehicle technology developed rapidly in 1970s, and gas-fueled vehicles skyrocketed after 1990s. Nowadays, the bi-fuel singlepoint injection system and mono-fuel closed-loop multipoint sequential fuel injection system came into being in succession, and the closed-loop multi-point sequential fuel injection system is the mainstream and direction of the electronic control technology of gas engine in the modern times. The exploration and application of the automatic control algorithm of the gas engine is the major studying content for relative scholars. Under this background, this paper analyzed the PID control, fuzzy control and fuzzy PID control algorithms [1-4], and targeted to explore the application result of these three algorithms in the controlling process of the idling system.

Numerous researchers had made contribution to the study of gas engine control, and it is these researchers' efforts that promoted the development of automatic control and the intellectualization process of gas engine. Among which: $\mathrm{Wu}$ Jianping (2010) studied the air-fuel ratio control strategy for gas engine in different operation conditions, and designed a kind of fuzzy PID dynamic switching control algorithm and simulated this algorithm in Simulink, and the result showed that this algorithm is of better real-time performance, stability and robustness [5]. Zhiming, et al. (2011) transformed the diesel engine of a certain model to make it applicable to gas generator set, to demarcate lean-burn and 1500RPM addition \& subtraction load, and demarcate the spark advance angle on electronic control system under the entire operating conditions [6]. Guo Shuqing (2006) developed a set of electronic control system for fuel feeding of CNG mono-fuel gas engine on the basis of foreign and domestic researches. This system adopted electronic control method to control the supply gas pressure, and the gas pressure target value can be adjusted as required. Compared with the first mechanical pressure reducer that currently widely used in China, it is featured with high control accuracy, etc. [7].

Base on previous studies, this paper analyzed the requirements on the idling system of the automobile gas engine and base on which, explored the design principles of PID control, fuzzy control and fuzzy PID control algorithm, so as to provide theoretical reference to the control of the idling system of the automobile gas engine.

\section{IDLING SYSTEM OF THE GAS ENGINE AND ITS PRINCIPLE DESCRIPTION}

The components of the idling system of the gas engine are as follows:

(1) Signal acquisition system: this system is a subsystem of the idling system, which plays its role to collect status information related to the engine and transmit to the control unit. The composition of the signal acquisition system includes: air flow sensor, throttle position sensor, speed sensor, coolant temperature sensor and corresponding signal processing circuit.

(2) Control unit: plays role to operate the information collected by the signal acquisition so as to determine the engine's operating state. It is the actuator for making control decisions and control instructions bearing drive

(3) Actuator: this component mainly includes idling stepping motor, ignition control system and paint spraying control system. 


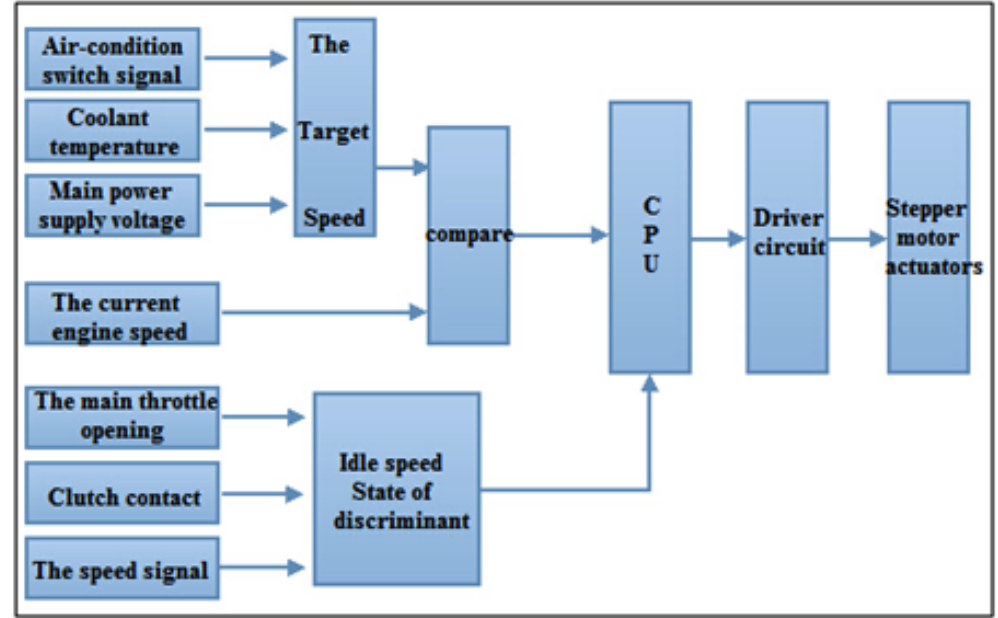

Fig. (1). The controlling process of the idle speed.

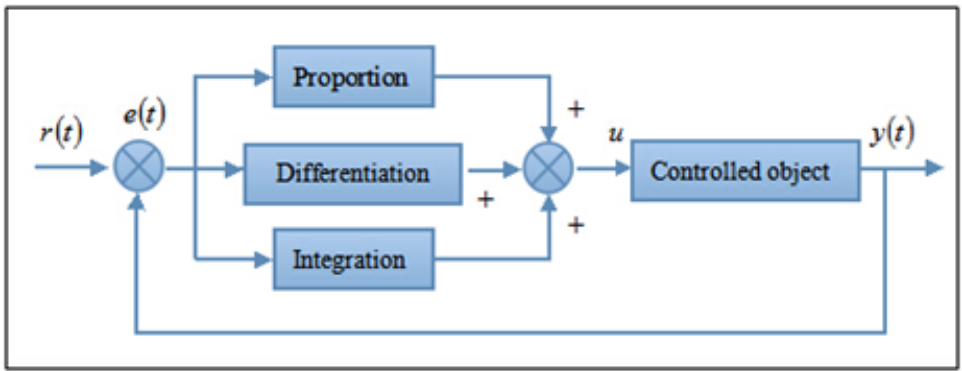

Fig. (2). Block diagram of PID control principle.

Xing Baojia (2009) stated that under the normal operation status, the engine output is controlled by the driver through controlling the throttle percentage by accelerator pedal and adjusting the air inflow. When the engine is at idle, the throttle is in inactive state; air enters the engine through the throttle gap and the idling bypass throttle, and controls the air injection according to its revolving speed and other correction signals. The idle running speed will change as the output speed and the internal resistance of the engine changed $[8,9]$.

Idle control device of the engine control system is used to automatically maintain the engine idle speed stability, which was proposed by Jun, et al. (1996) [10]. Idle control is realized by adjusting the air passage area and controlling the air flow, which was proposed by Jianfeng, et al. (2001) [11]. The main contents of idle control include engine load control and electrical load control, and the essence is to control the air inflow of the engine at idle. Air injection at idle is controlled by EUC according to the idling air-fuel ratio set in advance and the actual inflating volume. When the load of the engine at idle increased, EUC idle air control valve will increase the air inflow, thus the idle speed will be increased as well to prevent the engine from roughness or flameout. Conversely, EUC control the idle air control valve to decrease the air inflow, so as to decrease the idle speed to prevent from excessive idle speed $[12,13]$.

When the engine is at idle, throttle is in full- closed state and the engine is separates from the entire vehicle. The idle control mainly aims to maintain the stability of the revolving speed to balance the torque load through controlling the air flow by adjusting the passage area of the bypass air through stepping motor.

The controlling process of the idle speed is as shown in Fig. (1).

As shown in Fig. (1), firstly, EUC judge whether the engine is at idle according to the IDL signal, major throttle signal and vehicle speed signal, and if the engine is at idle, EUC will inquire corresponding target speed from the idle speed signal in the memorizer according to the coolant temperature sensor signal of the engine, air-conditioning switch, power steering switch, etc., and finally compare the target speed with the actual engine speed detected by the crankshaft position sensor. When the load of the engine increases, the engine is required to be at fast idle speed, while when the target speed is higher than the actual speed, EUC will control the idle air control valve to increase the bypass air inflow to realize idling. Conversely, when the load of the engine decreases, and the target speed is lower than the actual speed, EUC will control the idle air control valve to decrease the bypass air inflow to adjust the idle speed.

\section{PRINCIPLE OF CONTROL ALGORITHM}

\subsection{PID Control Principle And Its Controller Design}

PID control is a kind of linear controller, and its system principle is as shown in Fig. (2).

$r(t)$ in the Fig. (2) refers to the set value, $y(t)$ refers to the actual output value of the system, and $e(t)$ refers to the control deviation between the set value and the actual output 


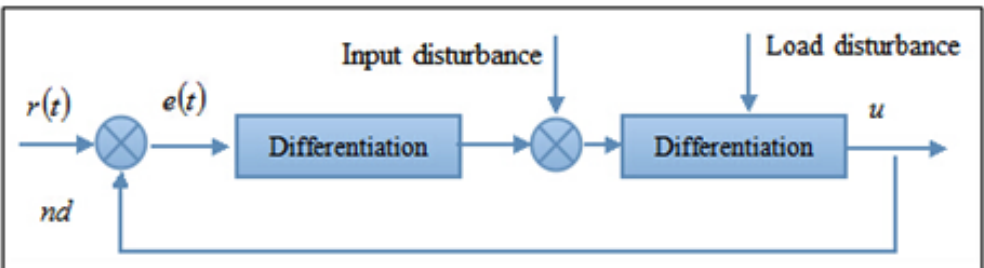

Fig. (3). Block diagram of PID idle speed control.

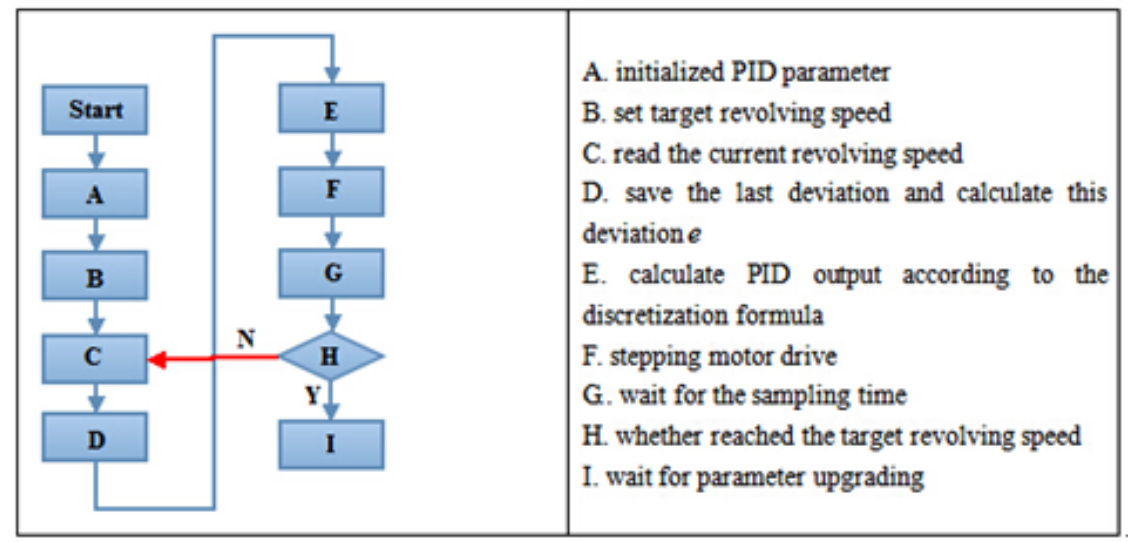

Fig. (4). Diagram for PID control process.

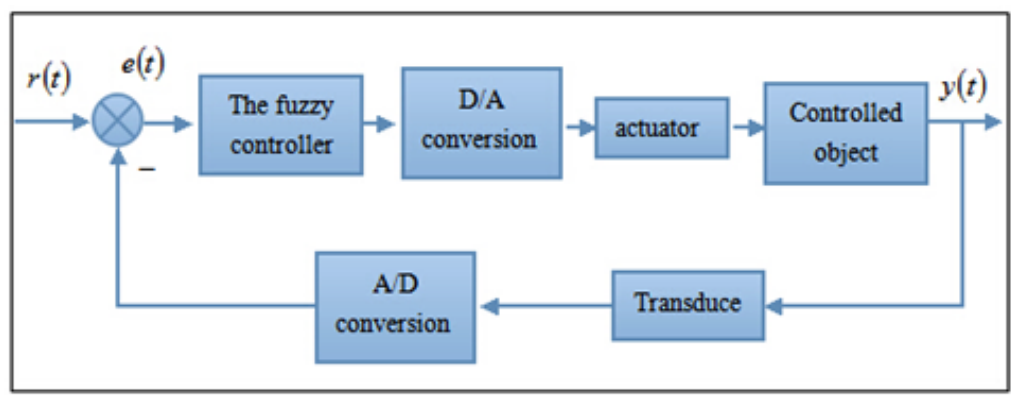

Fig. (5). Constitution diagram for the fuzzy control system.

value. The relationship among the three is as shown in formula (1).

$e(t)=r(t)-y(t)$

The control law of PID is as shown in formula (2)

$u(t)=k_{p} \cdot\left[e(t)+\frac{1}{T_{i}} \int_{0}^{t} e(t) d t+T_{d} \frac{d e(t)}{d t}\right]$

$k_{p}$ in formula (2) refers to the proportional constant, $T_{i}$ refers to integration constant, and $T_{d}$ refers to differential constant.

The control of PID idle speed is as shown in Fig. (3).

Expression of discrete PID is as shown in formula (3).

$u(k)=k_{p} e(k)+k_{i} \sum_{j=0}^{k} e(k)+k_{d}[e(k)-e(k-1)]$

$u(k)$ in formula (3) refers to the $k^{\text {th }}$ sample instant control output value, $e(k)$ refers to the inputted deviation value in the $k^{\text {th }}$ sampling instant and $e(k-1)$ refers to the $(k-1)$ inputted deviation value in the $(k-1)^{\text {th }}$ sampling instant. at idle control, the driving of the stepping motor is generally expressed by the PID controlled incremental formula as shown in formula (4).

$$
\begin{aligned}
\Delta u(k)= & k_{p}[e(k)-e(k-1)]+k_{i} e(k)+ \\
& k_{d}[e(k)-2 e(k-1)+e(k-2)]
\end{aligned}
$$

PID controlling process is as shown in Fig. (4).

\subsection{Fuzzy Control Algorithm}

Fuzzy control is a form of computer numerical control, and its constitution is as shown in the block Fig. (5).

In the Fig. (5), fuzzy controller is the core of the fuzzy control system. Application of D/A transformation makes the fuzzy controller will be according to the given value and is controlled by the differential feedback to as input, the corresponding controlled quantity is obtained after the synthesis of fuzzy control algorithm. As this controlled quantity are digital, while what the actuator received is analog quantity, therefore, D/A conversion is necessary between fuzzy controller and actuator. The actuator includes AC motor, DC 


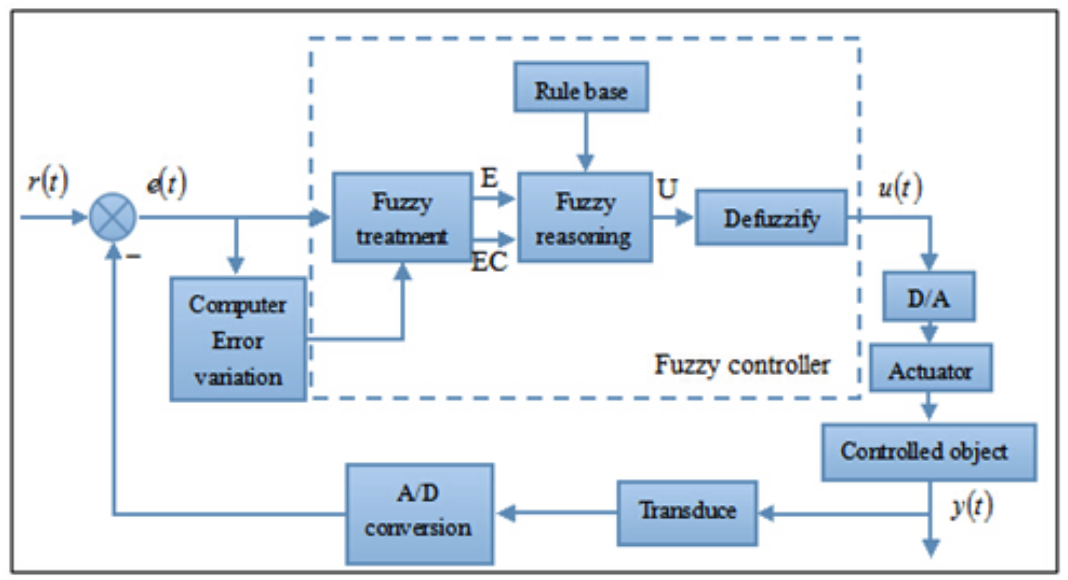

Fig. (6). Block diagram for the principle of the fuzzy controller.

motor, stepping motor, hydraulic motor, pneumatic control valve, etc. This paper targeted at idle instead of motor. The controlled object can be a device working under certain constraint conditions, so as to realize people's targets. These control objects can be clear or fuzzy, single variable or multiple variables, hysteretic or non-hysteretic, linear or nonlinear, constant or varying, and of strong coupling and interference, etc. Sensor aims to convert the controlled objects or controlled variables in various processes into signal, and A/D conversion aims to convert analog signals into digital signals, and feedback to the computer. It is notable that if the set value is different from the controlled variables, thus the dimensions on the digital quantity obtained from $\mathrm{A} / \mathrm{D}$ are necessary to be converted through computer.

The basic principle of the fuzzy controller is as shown in Fig. (6). The major contents-the fuzzy controlling steps are framed by imaginary lines. The contents in the imaginary lines include fuzzy extraction, fuzzy reasoning and defusing of the input quantity.

\subsection{Design Principles of the Fuzzy Controller}

Set the actual variation range of the input and output variables of the fuzzy controller as the basic domain of these variables, set $\mathrm{e}$ as the deviation, and $e$ as the changing rate of the deviation, thus the controlled quantity $u$ is expressed as formula (5).

$\left[-e_{\text {max }},+e_{\text {max }}\right]$
$\left[-\dot{e}_{\text {max }},+\dot{e}_{\text {max }}\right]$
$\left[-u_{\text {max }},+u_{\text {max }}\right]$

the domain of fuzzy set obtained by deviation linguistic variables E, the domain of fuzzy set obtained by deviation linguistic variables EC and the domain of fuzzy set obtained by linguistic variables of controlled quantity are as shown in formula (6).

$$
\left\{\begin{array}{l}
\mathbf{X}=\{-n,-n+1, \cdots, 0, \cdots, n-1, n\} \\
\mathbf{Y}=\{-m,-m+1, \cdots, 0, \cdots, m-1, m\} \\
\mathbf{Z}=\{-j,-j+1, \cdots, 0, \cdots, j-1, j\}
\end{array}\right.
$$

For the purpose of fuzzify the input, it is necessary to convert the input variable from basic domain to corresponding linguistic variable fuzzy set domain through quantification factor.

The core of the fuzzy controller of the principle is the fuzzy control, which can be expressed by multiple fuzzy conditional statements. The basic principle for establishing fuzzy control table lies in that, select the controlled quantity to eliminate the deviation as soon as possible when the deviation is large or relatively larger. Select the controlled quantity to prevent overshoot and based on the stability of the system when the deviation is smaller.

The fuzzy relation $\mathrm{R}$ of each rule can be calculated after the fuzzy rule is established, therefore, the overall fuzzy relation of the control rule of the entire system is as shown in formula (7).

$\mathbf{R}=R_{1} \vee R_{2} \vee \cdots \vee R_{n}$

If the input deviation linguistic variable $\mathrm{E}$ and deviation changing rate EC of the fuzzy controller are given, thus the output of the controlled quantity is as shown in formula (8).

$$
\mathrm{U}=(\mathrm{E} \times \mathrm{EC})^{\mathrm{T}} \circ \mathbf{R}
$$

As the output of the fuzzy reasoning is a fuzzy set, which reflected that the controlled quantity output linguistic variable belongs to its a combination of the membership size of all elements, including all information of the controlled quantity. The common fuzzy judgment methods include maximum membership degree, median judgment method and weighted mean method, among which the method of weighted mean is used most. If the output domain includes $n$ elements, the $i^{t h}$ element is expressed by $x_{i}$, and the membership of judgement output fuzzy set on element of each domain is $\mu_{u}\left(x_{i}\right)$. Take it as the weighting coefficient of the domain element $x_{i}$, thus the final judgment value of the weighted mean method is as shown in formula (9).

$u^{\prime}=\sum_{i=1}^{n} x_{i} \mu\left(x_{i}\right) / \sum_{i=1}^{n} \mu\left(x_{i}\right)$ 


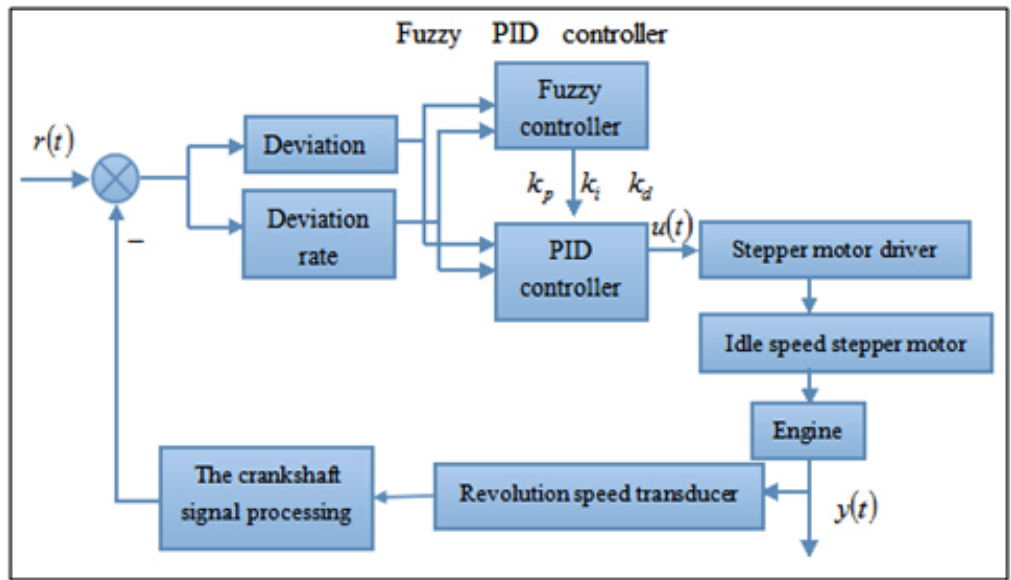

Fig. (7). Structure of idling fuzzy PID controller.

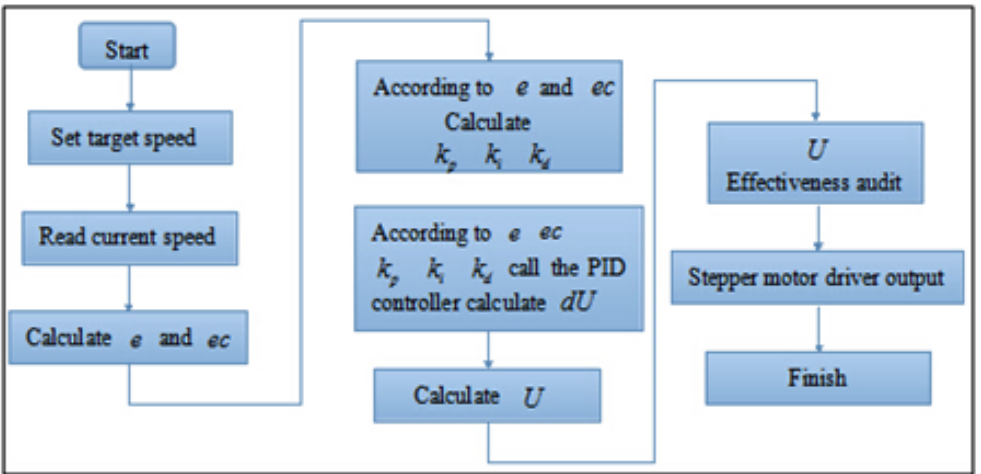

Fig. (8). Procedure chart of the fuzzy PID control.

\section{EMPIRICAL ANALYSIS ON THE COMPARISON BETWEEN THE DESIGN AND ALGORITHM OF THE IDLING FUZZY PID CONTROLLER}

\subsection{Structure Principle and Programming of Idling Fuzzy PID Controller}

Structure of idling fuzzy PID controller is as shown in Fig. (7).

As shown in Fig. (7), the fuzzy PID aims to fuzzy reason by calculating the current positional deviation and deviate changing rate and on the basis of fuzzy rules, and adjust the parameters by inquiring fuzzy matrix. Revolving speed value is converted to digital quantity through program processing by the pulse signal on the acquisition bent axle of the speed sensor, while $k_{p} k_{i} k_{d}$ are parameters of increment PID obtained from fuzzy reasoning, $u(t)$ refers to the stepping motor increment output by PID controller, which drive the idling stepping motor by stepper motor driving actuator, so as to change the air inflow and stabilize the revolving speed. The output quantity of the PID controller is calculated according to the formula (10).

$$
\begin{gathered}
u(k)=u(k-1)+k_{p} \Delta e(k)+k_{i} \Delta e(k) \\
+k_{d}[\Delta e(k)-\Delta e(k-1)]
\end{gathered}
$$

Self-adjusting requirements of controlled process on parameter $k_{p}$ and $k_{i}$ in case of different deviation and deviation changing rate: if the revolving speed exceeds the target too far, select smaller $k_{i}$ value, and larger $k_{p}$ value. The smaller $k_{i}$ value aims to slowly and smoothly recover the revolving speed near the target value, and the larger $k_{p}$ value aims to act as a damper to adjust the recovered speed. The larger $k_{p}$ value is able to prevent from overshoot. Within a small area near the target value, select larger $k_{p}$ and $k_{i}$ value, so as to actively treat any off-target action in time, and stabilize the revolving speed near the target value. Within the middle range, treat $k_{p}$ and $k_{i}$ properly. Select moderate $k_{p}$ value and smaller $k_{i}$ value to guarantee the response speed of the system. (8).

Procedure of the fuzzy PID control is as shown in Fig.

\subsection{Empirical Analysis and Comparison on Algorithms}

The comparison results on the cold start high idle speed control effects based on the PID control, fuzzy control and fuzzy PID control are as shown in Fig. (9):

The comparison results on the control effects of switching high idle speed to low idle speed based on the PID control, fuzzy control and fuzzy PID control are as shown in Fig. (10).

The comparison results on the control effects of switching low idle speed to high idle speed based on the PID control, fuzzy control and fuzzy PID control are as shown in Fig. (11). 


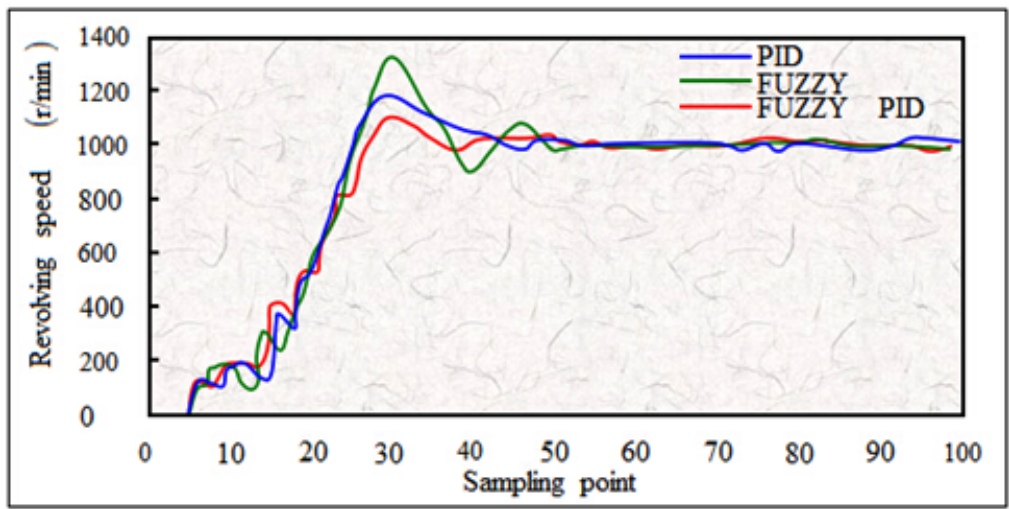

Fig. (9). The comparison results on the cold start high idle speed control effects based on the three kinds of algorithms.

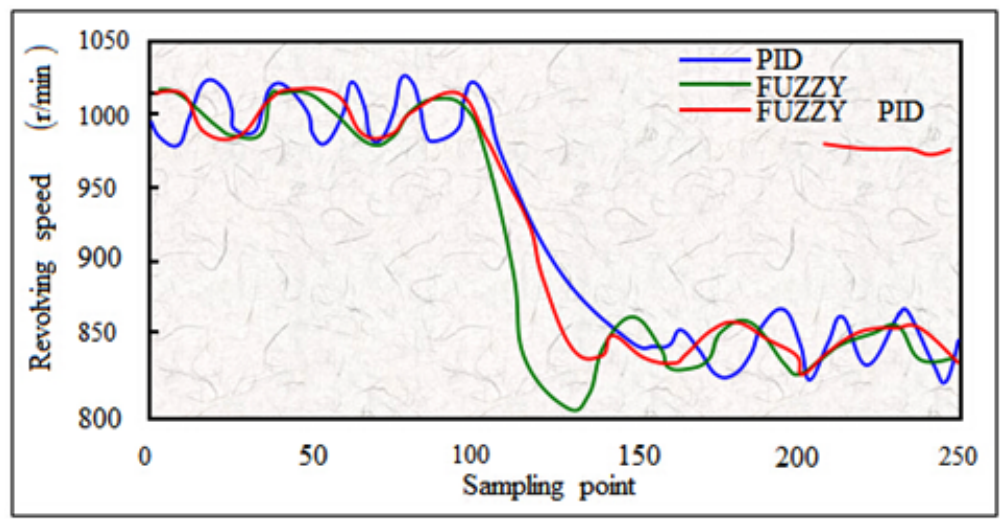

Fig. (10). The comparison results on the control effects of switching high idle speed to low idle speed based on the three kinds of algorithms.

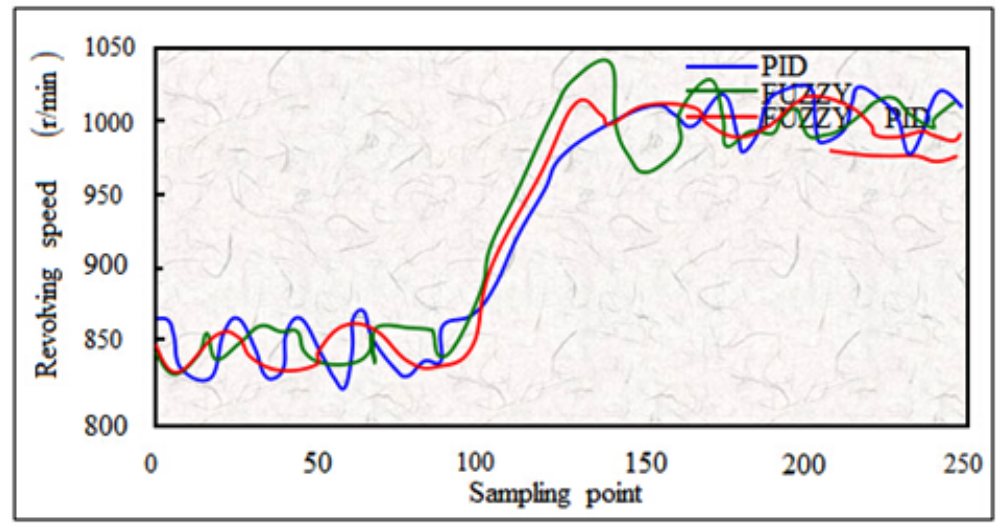

Fig. (11). The comparison results on the control effects of switching low idle speed to high idle speed based on the three kinds of algorithms.

It can be found from the contrastive effects of theses three algorithms in the process of cooling high idle start, switching high idle to low idle and switching low idle to high idle that the transient time of the PID control is the longest, while fuzzy control is of superiority to PID, but it needs longer vibrating time. Overshoot of the fuzzy PID control is smaller, and takes less time in adjusting. Therefore, the fuzzy PID control method studied in this paper is better for controlling.

\section{CONCLUSION}

This paper mainly studied PID control method, fuzzy control method and fuzzy PID control method, and concluded that the fuzzy PID control algorithm is a superior method through contrastive analysis on the control effects of theses three algorithm in the process of cooling high idle start, switching high idle to low idle and switching low idle to high idle.

\section{CONFLICT OF INTEREST}

The authors confirm that this article content has no conflict of interest.

\section{ACKNOWLEDGEMENTS}

The authors would like to acknowledge the following institutes for their financial support during completing this 
study: National 863 high-tech projects under project No. (2012AA111718).

\section{REFERENCES}

[1] S. Tzafestas, and N.P. Papanikolopoulos, "Incremental fuzzy expert PID control", IEEE Transactions on Industrial Electronics, vol. 37, no. 5, pp. 365-371, 1990.

[2] I. Pan, S. Das, and A. Gupta, "Tuning of an optimal fuzzy PID controller with stochastic algorithms for networked control systems with random time delay", ISA Transactions, vol. 50 , no. 1, pp. 2836, 2011.

[3] L. Zhou, and G. Zhao, "Application of fuzzy-PID control algorithm in uniform velocity temperature control system of resistance furnace", Chinese Journal of Scientific Instrument, vol. 29, no. 2, pp. 405, 2008.

[4] S. Soyguder, M. Karakose, and H. Alli, "Design and simulation of self-tuning PID-type fuzzy adaptive control for an expert HVAC system", Expert Systems with Applications, vol. 36, no. 3, pp. 4566-4573, 2009.

[5] J. Wu, Study on the Electronic Control Algorithm of Automobile Gas Engine, Chongqing University of Posts and Telecommunications, Chongqing, China, 2010.

[6] R.H. Ganesh, V. Subramanian, V. Balasubramanian, J.M. Mallikarjuna, A. Ramesh, and R.P. Sharma, "Hydrogen fueled spark igni- tion engine with electronically controlled manifold injection: An experimental study", Renewable Energy, vol. 33, no. 6, pp. 13241333, 2008.

[7] S. Guo, Study on Electronically Controlled Gas Pressure Regulation System of CNG Engine, Changchun University of Technology, 2006.

[8] W. Yang, W. Shi, and C. Chen, "Research on Vibration Isolation of Semi-Active Controlled Hydraulic Engine Mount with Air Spring", SAE International Journal of Passenger Cars-Mechanical Systems, vol. 7, no. 1, pp. 15-20, 2014

[9] B. Xing, Study on Design and Control of Idling System of Gas Engine, University of Science and Technology, Beijing, 2009.

[10] J.X. Wang, L. Yang, J. Feng, and B. Zhou, "Development of a new calibration system for electronic control units based on CCP", Transaction of CSICE, vol. 23, no. 2, pp. 147-154, 2005.

[11] U.G. Alkemade, and B. Schumann, "Engines and exhaust after treatment systems for future automotive applications". Solid State Ionics, vol. 177, no. 26, pp. 2291-2296, 2006.

[12] D. Karnopp, M.J. Crosby and R.A. Harwood, "Vibration control using semi-active force generators", Journal of Engineering for Industry, vol. 96, no. 2, pp. 619-626, 1974.

[13] G.M. Pietron, S.H. Lee, A.O. Gibson, Y. Fujii, R.L. Huffmaster, and P.J. Grutter, "Methods and Systems for Assisted Direct Start Control", U.S. Patent Application, US 8905896 B2, 2014.

Received: September 22, 2014

Revised: November 30, 2014

Accepted: December 02, 2014

(C) Xiaocheng et al.; Licensee Bentham Open.

This is an open access article licensed under the terms of the Creative Commons Attribution Non-Commercial License (http://creativecommons.org/licenses/by-nc/3.0/) which permits unrestricted, non-commercial use, distribution and reproduction in any medium, provided the work is properly cited. 